BRAVZULIAN JOURNAL

OF MEDICAL AND BIOLOGICAL RESHARCH

www.bjournal.com.br
ISSN 0100-879X

Volume 43 (5) 381-496 May 2011

BIOMEDICAL SCIENCES

AND

CLINICAL INVESTIGATION

Braz J Med Biol Res, May 2011, Volume 44(5) 411-417

doi: 10.1590/S0100-879X2011007500045

Ischemic post-conditioning attenuates the intestinal injury induced by limb ischemia/reperfusion in rats

Y.F. Leng, Y. Zhang, Y. Zhang, X. Xue, T. Wang and Y.Q. Kang

The Brazilian Journal of Medical and Biological Research is partially financed by

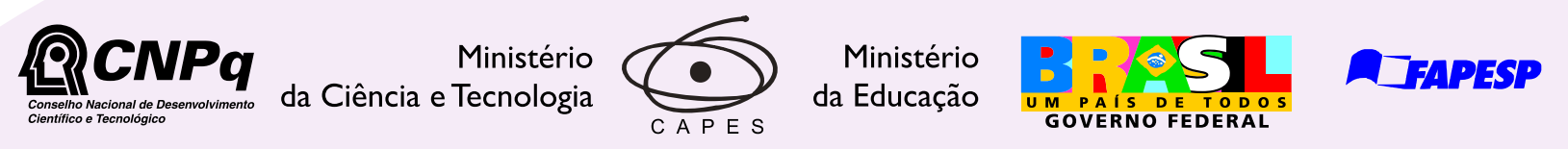

Institutional Sponsors
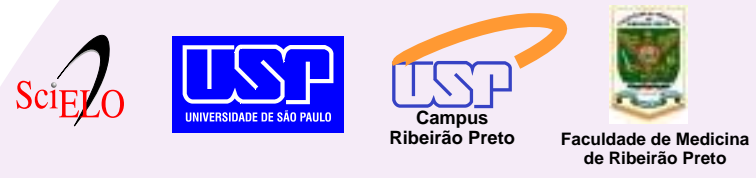

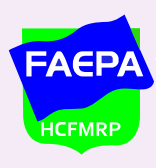

Ф SHIMADZU

GE Healthcare
Hotsite of proteomics metabolomics developped by:

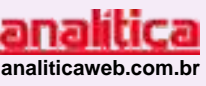

Thermo SCIENTIFIC 


\title{
Ischemic post-conditioning attenuates the intestinal injury induced by limb ischemia/reperfusion in rats
}

\author{
Y.F. Leng, Y. Zhang, Y. Zhang, X. Xue, T. Wang and Y.Q. Kang \\ Department of Anesthesiology, First Hospital, Lanzhou University, Lanzhou, Gansu, China
}

\begin{abstract}
The purpose of this study was to investigate the protective effects of ischemic post-conditioning on damage to the barrier function of the small intestine caused by limb ischemia-reperfusion injury. Male Wistar rats were randomly divided into 3 groups ( $\mathrm{N}$ = 36 each): sham operated (group S), lower limb ischemia-reperfusion (group LIR), and post-conditioning (group PC). Each group was divided into subgroups ( $\mathrm{N}=6$ ) according to reperfusion time: immediate $(0 \mathrm{~h}$; T1), $1 \mathrm{~h}(\mathrm{~T} 2), 3 \mathrm{~h}$ (T3), $6 \mathrm{~h}$ (T4), $12 \mathrm{~h}$ (T5), and $24 \mathrm{~h}$ (T6). In the PC group, 3 cycles of reperfusion followed by ischemia (each lasting $30 \mathrm{~s}$ ) were applied immediately. At all reperfusion times (T1-T6), diamine oxidase (DAO), superoxide dismutase (SOD), and myeloperoxidase (MPO) activity, malondialdehyde (MDA) intestinal tissue concentrations, plasma endotoxin concentrations, and serum DAO, tumor necrosis factor- $\alpha$ (TNF- $\alpha$ ), and interleukin-10 (IL-10) concentrations were measured in sacrificed rats. Chiu's pathology scores for small intestinal mucosa were determined under a light microscope and showed that damage to the small intestinal mucosa was lower in group PC than in group LIR. In group PC, tissue DAO and SOD concentrations at T2 to T6, and IL-10 concentrations at T2 to T5 were higher than in group LIR $(P<0.05)$; however, tissue MPO and MDA concentrations, and serum DAO and plasma endotoxin concentrations at T2 to T6, as well as TNF- $\alpha$ at T2 and T4 decreased significantly $(P<0.05)$. These results show that ischemic post-conditioning attenuated the permeability of the small intestines after limb ischemia-reperfusion injury. The protective mechanism of ischemic post-conditioning may be related to inhibition of oxygen free radicals and inflammatory cytokines that cause organ damage.
\end{abstract}

Key words: Post-conditioning; Limb ischemia-reperfusion injury; Small intestine

\section{Introduction}

Ischemia-reperfusion injury is caused by an abrupt restoration of the circulation after a prolonged ischemic insult and can result in significant morbidity after reconstructive surgery. Limb ischemia-reperfusion injury may be associated with both local and systemic proinflammatory responses, which can adversely affect patient outcomes. Limb ischemia-reperfusion injury has been observed in many clinical situations, including atherosclerosis, thrombosis or injury to the large vessels of the extremities, severe crush injuries, and surgery (1-3). Limb ischemia-reperfusion injury can lead to limb edema, skeletal muscle dysfunction, and necrosis and may progress to dysfunction and structural damage of other organs, such as the heart, lungs, brain, and small intestines $(4,5)$. Therefore, protection against limb ischemia-reperfusion injury has become an important focus of clinical research.

Ischemic post-conditioning, i.e., short periods of ischemia in remote vessels or distant organs, has been used to protect the myocardium from injury due to coronary artery occlusion-reperfusion (6-8). Studies have confirmed that ischemia post-conditioning may provide functional protection to the ischemic organ itself or to other organ systems, including skeletal muscles, from ischemia-reperfusion injury (9-12). However, to date, no reports on the protective effects of ischemic post-conditioning against damage to the small intestines from limb ischemia-reperfusion injury have been published. In the present study, a simulated limb ischemiareperfusion injury rat model was used to determine whether ischemic post-conditioning can prevent or reduce small intestine damage caused by limb ischemia-reperfusion injury. Markers that reflect changes in the barrier function and mechanism of damage to the small intestinal mucosa of rats were examined, and the degree of damage to the

Correspondence: Y.F. Leng, Department of Anesthesiology, First Hospital, Lanzhou University, Lanzhou 730000, Gansu, China. Fax: +86-931-861-9797. E-mail: lengyf@Izu.edu.cn

Received October 6, 2010. Accepted March 16, 2011. Available online April 8, 2011. Published May 16, 2011. 
small intestine was classified using Chiu's pathology grading system (13).

\section{Material and Methods}

\section{Experimental animals}

Atotal of 108 healthy male Wistar rats ( 6 months old; weight 220-250 g) were provided by the Medical Experimental Animal Center of the Gansu College of Traditional Chinese Medicine, China. The rats were randomly divided into 3 groups of 36 each: sham-operated group (group S), limb ischemia-reperfusion group (group LIR), and post-conditioning group (group PC). Each group was then divided into subgroups ( $N=6$ /group) according to reperfusion time after ischemia: immediately $(0$ h; T1), 1 h (T2), 3 h (T3), 6 h (T4), 12 h (T5), and 24 h (T6). All experiments were conducted according to the protocols approved by the Lanzhou University Animal Care and Use Committee.

\section{Animal model}

After a 12-h preoperative fast, with free access to water only, the rats were exposed to $2 \%$ isoflurane until loss of the righting reflex, and then fixed onto a seat-board on the operating table. The hind limbs of the rats were ligated with elastic rubber bands above the greater trochanter to completely block blood flow. Rats in group S(sham-operated group) were anesthetized, but did not undergo ligation. Rats in group LIR underwent ligation until the occurrence of complete ischemia of the lower limbs and the ligation was released after $3 \mathrm{~h}$ to restore blood flow to the hind limbs. Reperfusion was conducted for $1,3,6,12$, and $24 \mathrm{~h}$ (T2-T6). To test the protective effects of post-conditioning, group PC underwent 3 cycles of reperfusion followed by ischemia (each lasting $30 \mathrm{~s}$ ) immediately after $177 \mathrm{~min}$ of ischemia of the two lower limbs, followed by reperfusion for 1 , $3,6,12$, and $24 \mathrm{~h}$. After reperfusion, the rats were sacrificed under deep isoflurane anesthesia. Approximately $5 \mathrm{~mL}$ blood was drawn from the inferior vena cava and centrifuged at 495 $g$ for $15 \mathrm{~min}$ to separate the serum, which was then stored at $-20^{\circ} \mathrm{C}$ for further target detection. The small intestine (up to 5 $\mathrm{cm}$ from the ileocecal valve) was quickly removed and washed three times with normal saline. A 2-cm fragment of the small intestine was weighed and then placed in a vacuum oven, dried at $160^{\circ} \mathrm{C}$ for $48 \mathrm{~h}$ and weighed, and the small intestinal tissue wet to dry weight ratio (W/D ratio) of each group was calculated. Then, a $0.5-\mathrm{g}$ fragment of the small intestine was ground in a glass homogenizer to prepare a tissue homogenate. After centrifugation at $680 \mathrm{~g}$ for $20 \mathrm{~min}$, the resulting supernatant was diluted with normal saline and stored at $-20^{\circ} \mathrm{C}$ for further target analysis. The remaining fragments of the small intestine were fixed in $10 \%$ formalin, embedded in paraffin, stained with hematoxylin and eosin, sectioned, and classified using Chiu's pathology grading system (13) after examination under a light microscope. The Chiu's pathology grading system consists of five grades based on changes in villi and glands of the intestinal mucosa: grade 0 , normal mucosal villi; grade 1 , development of subepithelial Gruenhagen's space, usually at the apex of the villus, often with capillary congestion; grade 2, extension of the space with moderate lifting of the epithelial layer from the lamina propria; grade 3, massive epithelial lifting with a few denuded villi; grade 4, denuded villi with exposed capillaries; grade 5, disintegration of the lamina propria, and hemorrhage.

\section{Changes in the barrier functions and of the mechanism of damage to the small intestinal mucosa}

Plasma endotoxin concentrations were estimated using a quantitative chromogenic substrate assay (Xiamen TAL Experimental Plant Co., Ltd., China). Diamine oxidase (DAO) concentrations in the serum and small intestinal tissue of the rats were measured using a spectrophotometer with an automatic biochemical analyzer (Olympus - AU5400, Japan; provided by the Nanjing Jiancheng Bioengineering Institute, China). Superoxide dismutase (SOD), malondialdehyde (MDA), and myeloperoxidase (MPO) activity in the rat small intestinal tissue were measured by colorimetry (Nanjing Jiancheng Bioengineering Institute). Serum tumor necrosis factor- $\alpha$ (TNF- $\alpha$ ) and interleukin-10 (IL-10) concentrations were measured by enzyme-linked immunosorbent assay (Wuhan Booster Biological Technology, Ltd., China).

\section{Statistical analysis}

Data are reported as means $\pm S D$. One-way analysis of variance (ANOVA) was used to determine statistically significant differences between groups using SPSS version 17.0 for Windows (SPSS Inc., USA).

\section{Results}

\section{Pathological changes in the rat small intestine}

The microstructure of the small intestine of group $S$ was normal. The small intestinal tissue of groups LIR and PC showed varying degrees of pathological changes, but the damage in group PC was less than that seen in group LIR at T3 to T6 (P $<0.05)$. Chiu's pathology grading scores corresponding to the changes in reperfusion times are shown in Table 1. In the LIR and PC groups, pathological damage gradually increased with reperfusion time, peaking at $\mathrm{T} 4$, and then decreasing.

\section{Changes in the barrier function and damage mechanism of the small intestinal mucosa}

In the LIR and PC groups, serum DAO and plasma endotoxin concentrations increased at all reperfusion times (T1-T6) compared to group $S(P<0.05)$, whereas tissue DAO concentrations decreased $(P<0.05)$. Compared with times T2 to T6 for the LIR group, the tissue DAO activity of group PC increased $(P<0.05)$, and the serum DAO activity and plasma endotoxin concentration decreased $(P<0.05)$. Compared to other reperfusion times for groups LIR and PC, tissue and serum DAO activity as well as plasma endotoxin concentrations reached peak values at reperfusion time T4 $(P<0.05)$ for comparison to other time (Figure 1). 
In the LIR and PC groups, small intestinal tissue W/D ratio, MPO and MDA activity and serum IL-10 (at T1-T6) and TNF- $\alpha$ (at T1-T4) concentrations were higher than those in group $S$
$(P<0.05)$, and tissue SOD activity at T1 to T6 was lower $(P<$ 0.05). Tissue SOD activity at T2 to T6 and serum IL-10 at T2 to $\mathrm{T} 5$ were significantly higher in the PC group than in the LIR

Table 1. Chiu's pathological grading of the small intestine in the rat groups studied.

\begin{tabular}{lcccccc}
\hline Group & T1 & T2 & T3 & T4 & T5 & T6 \\
\hline Group S & 0 & 0 & 0 & 0 & 0 & 0 \\
Group LIR & $1.17 \pm 0.75^{\mathrm{ae}}$ & $1.67 \pm 0.55^{\mathrm{ae}}$ & $2.50 \pm 0.52^{\mathrm{ac}}$ & $3.50 \pm 0.41^{\mathrm{ace}}$ & $3.17 \pm 0.52^{\mathrm{ac}}$ & $2.67 \pm 0.55^{\mathrm{acd}}$ \\
Group PC & $1.17 \pm 0.75^{\mathrm{a}}$ & $1.33 \pm 0.52^{\mathrm{a}}$ & $1.50 \pm 0.55^{\mathrm{ab}}$ & $2.17 \pm 0.52^{\mathrm{abce}}$ & $1.83 \pm 0.55^{\mathrm{abc}}$ & $1.50 \pm 0.52^{\mathrm{abd}}$ \\
\hline
\end{tabular}

Data are reported as the mean Chiu's grade \pm SD for 6 rats in each subgroup. Criteria of Chiu grading: grade 0 , normal mucosa villi; grade 1, development of subepithelial Gruenhagen's space, usually at the apex of the villus and often with capillary congestion; grade 2, extension of the space with moderate lifting of epithelial layer from the lamina propria; grade 3, massive epithelial lifting with a few denuded villi; grade 4, denuded villi with exposed capillaries; grade 5, disintegration of the lamina propria, ulceration and hemorrhage. Group S: sham-operated group; group LIR: limb ischemia-reperfusion group; group PC: post-conditioning group. Reperfusion time: $\mathrm{T} 1=$ immediate $(0 \mathrm{~h}) ; \mathrm{T} 2=1 \mathrm{~h} ; \mathrm{T} 3=3 \mathrm{~h} ; \mathrm{T} 4=6 \mathrm{~h} ; \mathrm{T} 5=12 \mathrm{~h} ; \mathrm{T} 6=24 \mathrm{~h}$. aP $<0.05$ vs group $\mathrm{S}$; ${ }^{\mathrm{b} P}<0.05$ vs group LIR; ${ }^{\mathrm{P}}<0.05$ vs T1; ${ }^{\mathrm{P}} \mathrm{P}<0.05$ vs T4; ${ }^{\mathrm{P}} \mathrm{P}<0.05$ vs T6 (one-way ANOVA).
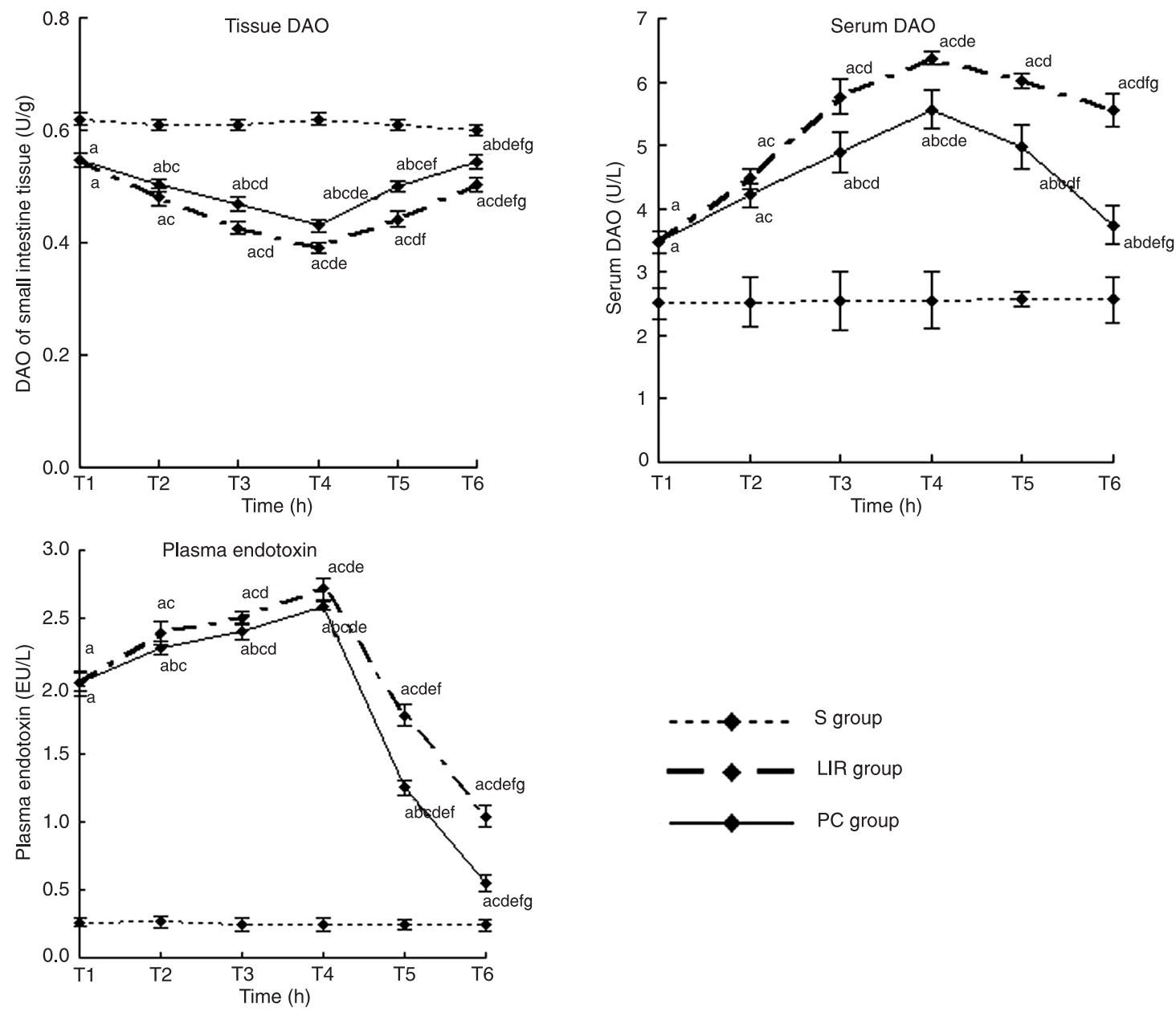

Figure 1. Effect of limb ischemia and reperfusion on intestinal tissue diamine oxidase (DAO), serum DAO and plasma endotoxin concentrations in the rat. Group S: sham-operated group; group LIR: limb ischemia-reperfusion group, and group PC: post-conditioning group. Data are reported as means \pm SD for 6 rats in each group. Reperfusion time: T1 $=$ immediate $(0 \mathrm{~h}) ; \mathrm{T} 2=1 \mathrm{~h} ; \mathrm{T} 3=3 \mathrm{~h} ; \mathrm{T} 4=6$ h; T5 = 12 h, and T6 = 24 h. aP $<0.05$ vs group S; bP $<0.05$ vs group LIR; ${ }^{C P}<0.05$ vs T1; ${ }^{d P}<0.05$ vs T2; eP $<0.05$ vs T3; fP $<0.05$ vs T4; gP $<0.05$ vs T5 (one-way ANOVA). 
group $(P<0.05)$; however, tissue MPO activity and W/D ratio at $\mathrm{T} 3$ to $\mathrm{T} 6$ and tissue MDA concentrations at $\mathrm{T} 2$ to T6, as well as serum TNF- $\alpha$ concentrations at T2 and T4 decreased $(P<0.05)$. Tissue MDA concentrations, W/D ratio, SOD and MPO activity reached peak values at T4 ( $P$ $<0.05$ ) in the LIR and PC groups. Serum TNF- $\alpha$ concen-
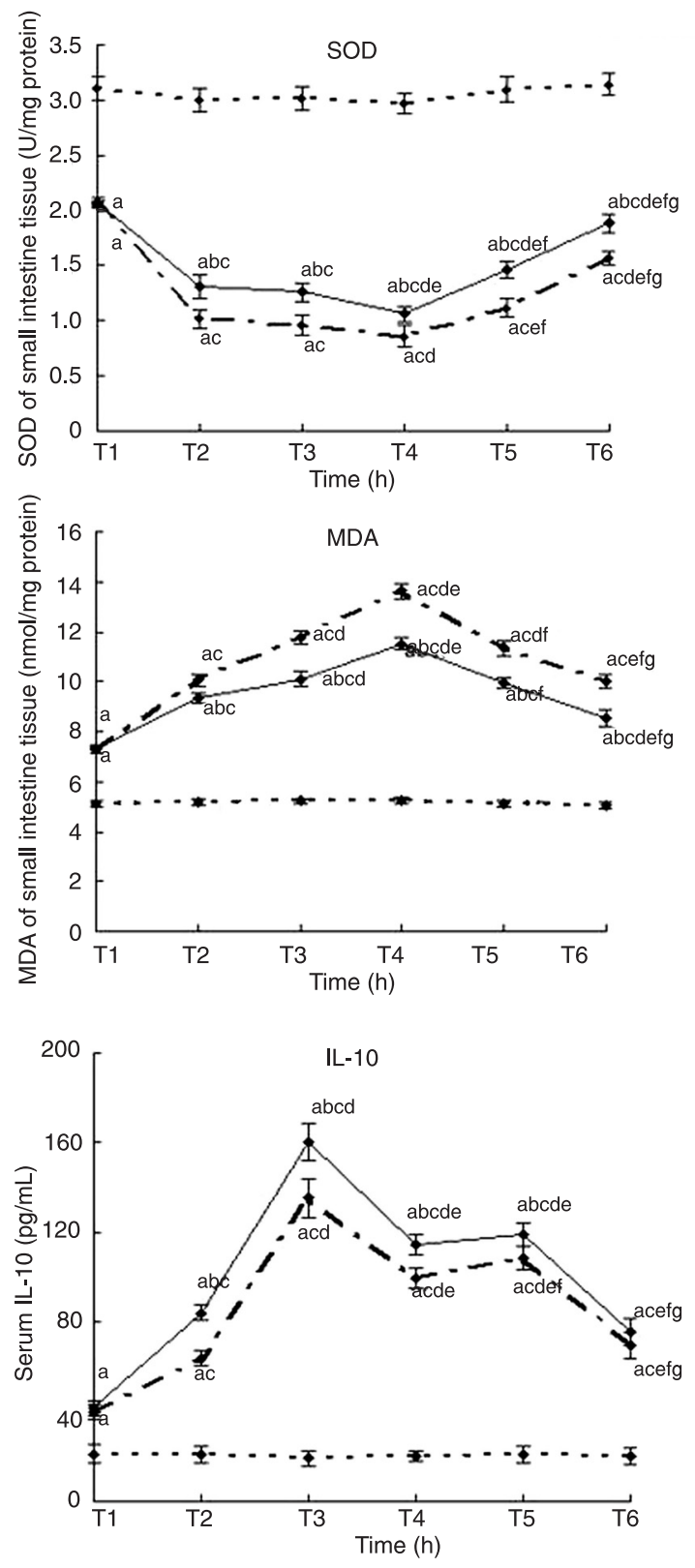

trations reached a peak at T2 $(P<0.05)$. After T2, serum TNF- $\alpha$ concentration gradually decreased and reached the same concentration as group $S$ at $T 5$ and T6 $(P \geq 0.05)$. Concentrations of IL-10 were highest at T3 $(P<0.05)$. Even at times $\mathrm{T} 4$ and $\mathrm{T} 5$, serum IL-10 concentration remained relatively high (Figure 2 ).
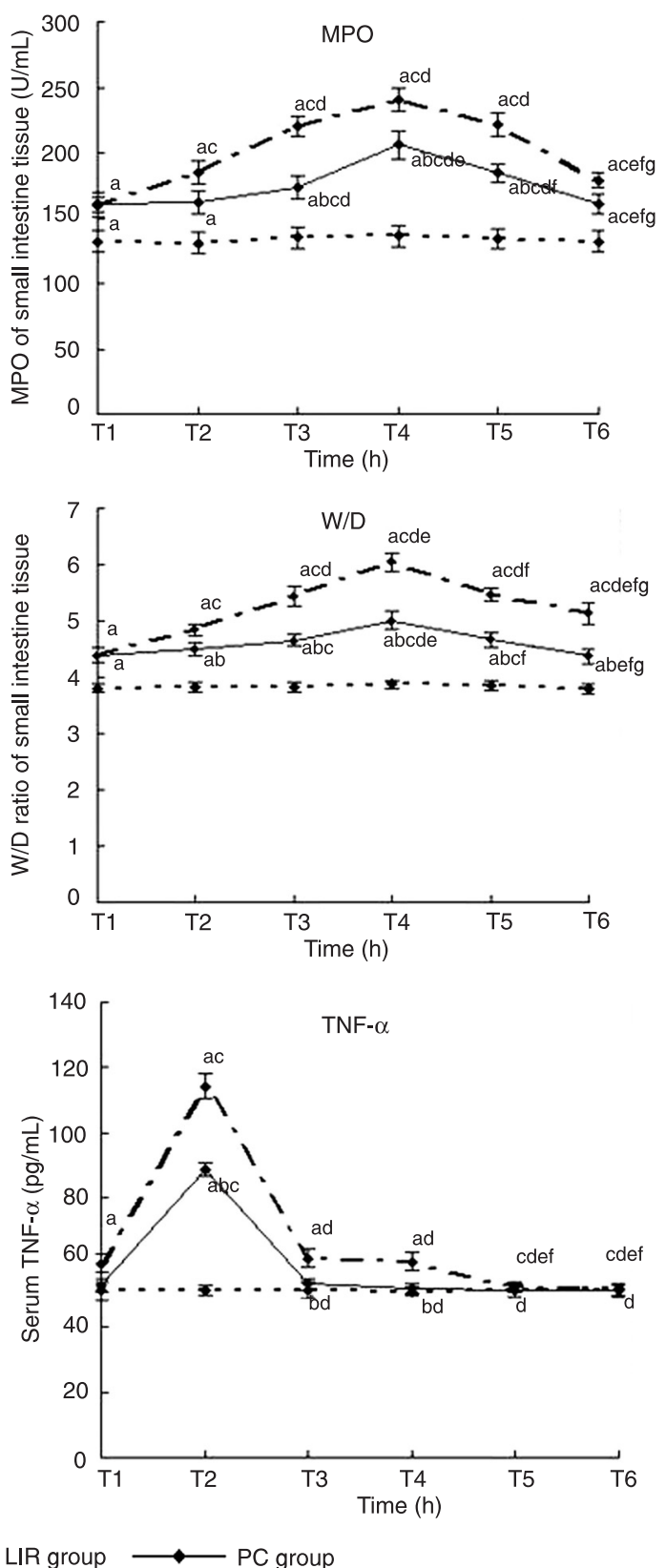

Figure 2. Effect of limb ischemia and reperfusion on superoxide dismutase (SOD), myeloperoxidase (MPO), malondialdehyde (MDA) concentrations and wet to dry weight ratio (W/D ratio) of small intestinal tissue, serum interleukin-10 (IL-10), and tumor necrosis factor- $\alpha$ (TNF- $\alpha$ ) with repefusion times in the rat groups. Group S: sham-operated group; group LIR: limb ischemia-reperfusion group, and group PC: post-conditioning group. Reperfusion time: T1 = immediate $(0 \mathrm{~h}) ; \mathrm{T} 2=1 \mathrm{~h}$; T3 = $3 \mathrm{~h}$; T4 = $6 \mathrm{~h}$; T5 = $12 \mathrm{~h}$, and T6 = 24 h. Data are reported as means \pm SD for 6 rats in each group. aP $<0.05$ vs group S; bP $<0.05$ vs group LIR; ${ }^{c P}<0.05$ vs $T 1$; ${ }^{d P}<0.05$ vs T2; ${ }^{\mathrm{P}}<0.05$ vs T3; ${ }^{\mathrm{f}} \mathrm{P}<0.05$ vs T4; $\mathrm{P} P<0.05$ vs $\mathrm{T} 5$ (one-way ANOVA). 


\section{Discussion}

Ischemia-reperfusion injury of the gastrointestinal tract not only causes damage to the function of the gastrointestinal tract, but may also be a factor in the development of multiple organ dysfunction syndrome (MODS) associated with reperfusion injury $(14,15)$. The results of the current study showed that at different times of reperfusion following limb ischemia, when varying degrees of small intestinal mucosal damage occurred, the small intestinal tissue DAO activity - which has been a major indicator of the integrity and functional mass of the intestinal mucosa (16) - was lower in the LIR group than in the $S$ group (the sham-operated group). However, the serum DAO concentrations were significantly higher, indicating that the mucous membrane barrier of the rat small intestine was destroyed and gut permeability changed, leading to a release of intestinal DAO into the bloodstream. Diamine oxidase is an enzyme primarily synthesized in gastrointestinal mucosal cells and closely reflects the maturity and integrity of the gastrointestinal mucosa $(17,18)$.

Plasma endotoxin concentrations were higher in the LIR group than in the $S$ group. When intestinal mucosal integrity is disrupted following shock, burns, abdominal aortic surgery, liver disease, or ischemia-reperfusion injury, an increase occurs in intestinal permeability and translocation of bacterial endotoxin, as well as in plasma endotoxin $(19,20)$. When the intestinal barrier is injured by lower limb ischemia-reperfusion, gastrointestinal endotoxins may enter the extraintestinal tissues and produce free radicals and cytokines that may potentiate the development of MODS $(21,22)$.

Limb ischemia-reperfusion injury, leading to changes in the permeability of the intestinal mucosa, may be closely related to the production of excess oxygen free radicals $(15,16,23,24)$. The production of reactive oxygen metabolites during ischemia-reperfusion involves oxidases found in resident phagocytic cells as well as microvascular and mucosal epithelial cells (25). In the present study, the small intestinal tissue SOD activity of group LIR during reperfusion was lower than that of group $S$, but the small intestinal tissue MPO activity and MDA concentrations were higher. This suggests that an increase in oxygen free radicals and lipid peroxidation occurs, resulting in changes in the pathophysiology of the intestinal mucosa with mucosal epithelial damage, edema, and activation of immuno-inflammatory cells. SOD is a key enzyme that eliminates free radicals by converting superoxide anions to hydrogen peroxide, which is then removed by glutathione peroxidase and catalase. Large numbers of oxygen free radicals are generated during periods of ischemia followed by reperfusion, leading to excessive SOD consumption (26). In contrast, MPO is released upon activation to catalyze the formation of oxidants, can lead to tissue damage during chronic inflammation, and serves as a major enzymatic catalyst of lipid peroxidation at the site of inflammation (27). MDA is a naturally occurring product of lipid peroxidation and prostaglandin biosynthesis that is mutagenic and carcinogenic. In the present study, we determined MDA in order to estimate lipid peroxidation in damaged tissue.

Many researchers believed ischemic post-conditioning to have a protective effect on cardiac tissue against ischemiareperfusion injury by inhibiting myocardial injury and reducing myocardial infarct size $(6,28)$. In recent years, studies on the mechanism by which post-conditioning protected other organs against ischemia-reperfusion injury have increased. In cerebral ischemia, hypoxia-inducible factor-1 $\alpha$ expression and its target genes, erythropoietin and adrenomedullin, are increased by hypoxic post-conditioning (10), and MPO activity and expressions of IL-1 $\beta$, TNF- $\alpha$, and intercellular adhesion molecule-1 (ICAM-1) are also decreased by postconditioning (29). Serviddio et al. (11) observed that postconditioning may reduce impairment of the mitochondrial respiratory chain, mitochondrial peroxide production, and protein damage in renal ischemia-reperfusion injury. Postconditioning also decreased inflammatory cell infiltration, MPO activity, and wet-weight of post-conditioned muscle in digitorum longus skeletal muscle ischemia-reperfusion injury (12). In the present study, ischemic post-conditioning significantly reduced the pathological damage to the small intestine caused by lower limb ischemia-reperfusion injury. Although this damage was inevitable, the small intestinal injury in the PC group was less severe than that of the LIR group. During ischemia-reperfusion, the injured tissues (the ischemic tissue itself as well as remote organs) release a large number of inflammatory cytokines, including rapidly produced TNF- $\alpha$; inflammatory cells accumulate and intestinal inflammatory damage occurs (30-32). IL-10 modulates pro-inflammatory cytokine production and tissue injury following ischemia-reperfusion injury. The exogenous administration of IL-10 produced an effect associated with the inhibition of cytokine production and neutrophil accumulation in a rodent model of intestinal reperfusion injury $(33,34)$. Ischemic post-conditioning can effectively lower the serum concentrations of DAO, TNF- $\alpha$, and plasma endotoxin, but may promote the production of the anti-inflammatory factor IL-10. The present results show decreases in serum concentrations of TNF- $\alpha$ and increases in IL-10, either as consequences of intestinal tissue improvement or systemic repercussions of post-conditioning, which stimulate limb ischemia tissue in an action probably mediated by nitric oxide (35). A high concentration of IL-10 entering the blood circulation can inhibit overproduction of oxygen free radicals and inflammatory factor TNF- $\alpha$, which induce the intestinal injury, and, in turn, effectively lower the blood concentrations of DAO and endotoxin, which increase the inflammatory response. At the same time, IL-10 might increase SOD activity and reduce both MPO activity and MDA concentrations.

Ischemic post-conditioning can improve the small 
intestinal mucosal injury induced by lower limb ischemiareperfusion injury. It increases SOD activity to scavenge oxygen free radicals, reduces the production of the inflammatory cytokine TNF- $\alpha$, and increases the production of the anti-inflammatory factor IL-10. The attenuating action of ischemic post-conditioning on ischemia-reperfusion injury may be controlled by several mechanisms, which require further investigation. Based on the findings of the present study, ischemic post-conditioning may have clinical

\section{References}

1. Christ F, Moser CM, Niklas M, Gartside IB, Gamble J, Refior $\mathrm{HJ}$, et al. Prevalence of cyclic changes in limb volume (volumotion) of male patients with knee injury and the effects of ischemia/reperfusion due to tourniquet. Int $J$ Microcirc Clin Exp 1995; 15: 14-20.

2. Mathru M, Dries DJ, Barnes L, Tonino P, Sukhani R, Rooney MW. Tourniquet-induced exsanguination in patients requiring lower limb surgery. An ischemia-reperfusion model of oxidant and antioxidant metabolism. Anesthesiology 1996; 84: 14-22.

3. Soong CV, Blair PH, Halliday MI, McCaigue MD, Hood JM, Rowlands BJ, et al. Bowel ischaemia and organ impairment in elective abdominal aortic aneurysm repair. $\mathrm{Br} J$ Surg 1994; 81: 965-968.

4. Soong CV, Young IS, Lightbody JH, Hood JM, Rowlands BJ, Trimble ER, et al. Reduction of free radical generation minimises lower limb swelling following femoropopliteal bypass surgery. Eur J Vasc Surg 1994; 8: 435-440.

5. Wehrens XH, Rouwet EV, oude Egbrink MG, Slaaf DW, Ramsay G. Effects of experimental lower-limb ischaemiareperfusion injury on the mesenteric microcirculation. $\mathrm{Br} \mathrm{J}$ Surg 2002; 89: 185-191.

6. Zhao ZQ, Corvera JS, Halkos ME, Kerendi F, Wang NP, Guyton RA, et al. Inhibition of myocardial injury by ischemic postconditioning during reperfusion: comparison with ischemic preconditioning. Am J Physiol Heart Circ Physiol 2003; 285: H579-H588.

7. Galagudza M, Kurapeev D, Minasian S, Valen G, Vaage J. Ischemic postconditioning: brief ischemia during reperfusion converts persistent ventricular fibrillation into regular rhythm. Eur J Cardiothorac Surg 2004; 25: 1006-1010.

8. Philipp S, Yang XM, Cui L, Davis AM, Downey JM, Cohen MV. Postconditioning protects rabbit hearts through a protein kinase C-adenosine A2b receptor cascade. Cardiovasc Res 2006; 70: 308-314.

9. de Rougemont O, Lehmann K, Clavien PA. Preconditioning, organ preservation, and postconditioning to prevent ischemia-reperfusion injury to the liver. Liver Transp/ 2009; 15: $1172-1182$.

10. Leconte C, Tixier E, Freret T, Toutain J, Saulnier R, Boulouard $\mathrm{M}$, et al. Delayed hypoxic postconditioning protects against cerebral ischemia in the mouse. Stroke 2009; 40: 3349-3355.

11. Serviddio G, Romano AD, Gesualdo L, Tamborra R, Di Palma AM, Rollo T, et al. Postconditioning is an effective strategy to reduce renal ischaemia/reperfusion injury. Nephrol Dial Transplant 2008; 23: 1504-1512. relevance for patients in intensive care units.

\section{Acknowledgments}

We would like to thank Lanzhou City Development Plan of Science and Technology for financial support (grant \#2009-1-52). We also wish to thank Dr. Gen Chen, School of Basic Medical Science of Lanzhou University, for providing a laboratory to our group.
12. Park JW, Kang JW, Jeon WJ, Na HS. Postconditioning protects skeletal muscle from ischemia-reperfusion injury. Microsurgery 2010; 30: 223-229.

13. Chiu CJ, McArdle AH, Brown R, Scott HJ, Gurd FN. Intestinal mucosal lesion in low-flow states. I. A morphological, hemodynamic, and metabolic reappraisal. Arch Surg 1970; 101: 478-483.

14. Defraigne JO, Pincemail J. Local and systemic consequences of severe ischaemia and reperfusion of the skeletal muscle. Pathophysiology and prevention. Acta Chir Belg 1997; 97: 176-186.

15. Yassin MM, Barros D'Sa AA, Parks TG, McCaigue MD, Leggett $P$, Halliday MI, et al. Lower limb ischaemia-reperfusion injury alters gastrointestinal structure and function. $\mathrm{Br} J$ Surg 1997; 84: 1425-1429.

16. Wolvekamp MC, de Bruin RW. Diamine oxidase: an overview of historical, biochemical and functional aspects. Dig Dis 1994; 12: 2-14.

17. Kazmierczak SC, Robertson AF. Evaluation of a spectrophotometric method for measurement of activity of diamine oxidase in newborn infants. Ann Clin Lab Sci 1992; 22: 155161.

18. Stechmiller JK, Treloar D, Allen N. Gut dysfunction in critically ill patients: a review of the literature. Am J Crit Care 1997; 6: 204-209.

19. Demirkan A, Savas B, Melli M. Endotoxin level in ischemiareperfusion injury in rats: effect of glutamine pretreatment on endotoxin levels and gut morphology. Nutrition 2010; 26: 106-111.

20. Corson RJ, Paterson IS, O'Dwyer ST, Rowland P, Kirkman E, Little RA, et al. Lower limb ischaemia and reperfusion alters gut permeability. Eur J Vasc Surg 1992; 6: 158-163.

21. Edrees WK, Lau LL, Young IS, Smye MG, Gardiner KR, Lee $B$, et al. The effect of lower limb ischaemia-reperfusion on intestinal permeability and the systemic inflammatory response. Eur J Vasc Endovasc Surg 2003; 25: 330-335.

22. Yassin MM, Barros D'Sa AA, Parks TG, Soong CV, Halliday $\mathrm{MI}$, McCaigue MD, et al. Lower limb ischaemia-reperfusion injury causes endotoxaemia and endogenous antiendotoxin antibody consumption but not bacterial translocation. $\mathrm{Br} \mathrm{J}$ Surg 1998; 85: 785-789.

23. Mullane KM, Kraemer R, Smith B. Myeloperoxidase activity as a quantitative assessment of neutrophil infiltration into ischemic myocardium. J Pharmacol Methods 1985; 14: 157167.

24. Deitch EA, Taylor M, Grisham M, Ma L, Bridges W, Berg $R$. Endotoxin induces bacterial translocation and increases 
xanthine oxidase activity. J Trauma 1989; 29: 1679-1683.

25. Gedik E, Girgin S, Ozturk H, Obay BD, Ozturk H, Buyukbayram $\mathrm{H}$. Resveratrol attenuates oxidative stress and histological alterations induced by liver ischemia/reperfusion in rats. World J Gastroenterol 2008; 14: 7101-7106.

26. Roth E, Hejjel L, Jaberansari M, Jancso G. The role of free radicals in endogenous adaptation and intracellular signals. Exp Clin Cardiol 2004; 9: 13-16.

27. Zhang R, Brennan ML, Shen Z, MacPherson JC, Schmitt D, Molenda CE, et al. Myeloperoxidase functions as a major enzymatic catalyst for initiation of lipid peroxidation at sites of inflammation. J Biol Chem 2002; 277: 46116-46122.

28. Yin Z, Gao H, Wang H, Li L, Di C, Luan R, et al. Ischaemic post-conditioning protects both adult and aged SpragueDawley rat heart from ischaemia-reperfusion injury through the phosphatidylinositol 3-kinase-AKT and glycogen synthase kinase-3beta pathways. Clin Exp Pharmacol Physiol 2009; 36: 756-763.

29. Caty MG, Guice KS, Oldham KT, Remick DG, Kunkel SI. Evidence for tumor necrosis factor-induced pulmonary microvascular injury after intestinal ischemia-reperfusion injury. Ann Surg 1990; 212: 694-700.

30. Xing B, Chen H, Zhang M, Zhao D, Jiang R, Liu X, et al. Ischemic post-conditioning protects brain and reduces inflammation in a rat model of focal cerebral ischemia/rep- erfusion. J Neurochem 2008; 105: 1737-1745.

31. Souza DG, Soares AC, Pinho V, Torloni H, Reis LF, Teixeira $\mathrm{MM}$, et al. Increased mortality and inflammation in tumor necrosis factor-stimulated gene-14 transgenic mice after ischemia and reperfusion injury. Am J Pathol 2002; 160: $1755-1765$.

32. Lane JS, Todd KE, Lewis MP, Gloor B, Ashley SW, Reber $\mathrm{HA}$, et al. Interleukin-10 reduces the systemic inflammatory response in a murine model of intestinal ischemia/reperfusion. Surgery 1997; 122: 288-294.

33. Souza DG, Guabiraba R, Pinho V, Bristow A, Poole S, Teixeira MM. IL-1-driven endogenous IL-10 production protects against the systemic and local acute inflammatory response following intestinal reperfusion injury. J Immunol 2003; 170: 4759-4766.

34. Souza DG, Teixeira MM. The balance between the production of tumor necrosis factor-alpha and interleukin-10 determines tissue injury and lethality during intestinal ischemia and reperfusion. Mem Inst Oswaldo Cruz 2005; 100 (Suppl 1): $59-66$.

35. Serafin A, Rosello-Catafau J, Prats N, Gelpi E, Rodes J, Peralta C. Ischemic preconditioning affects interleukin release in fatty livers of rats undergoing ischemia/reperfusion. Hepatology 2004; 39: 688-698. 